Division of Geological \& Geophysical Surveys

RAW DATA FILE 2012-4

\title{
SPATIALLY REFERENCED OBLIQUE AERIAL IMAGERY OF THE GOLOVIN SHORELINE, JULY 2012
}

by

Meagan R. DeRaps and Nicole E.M. Kinsman

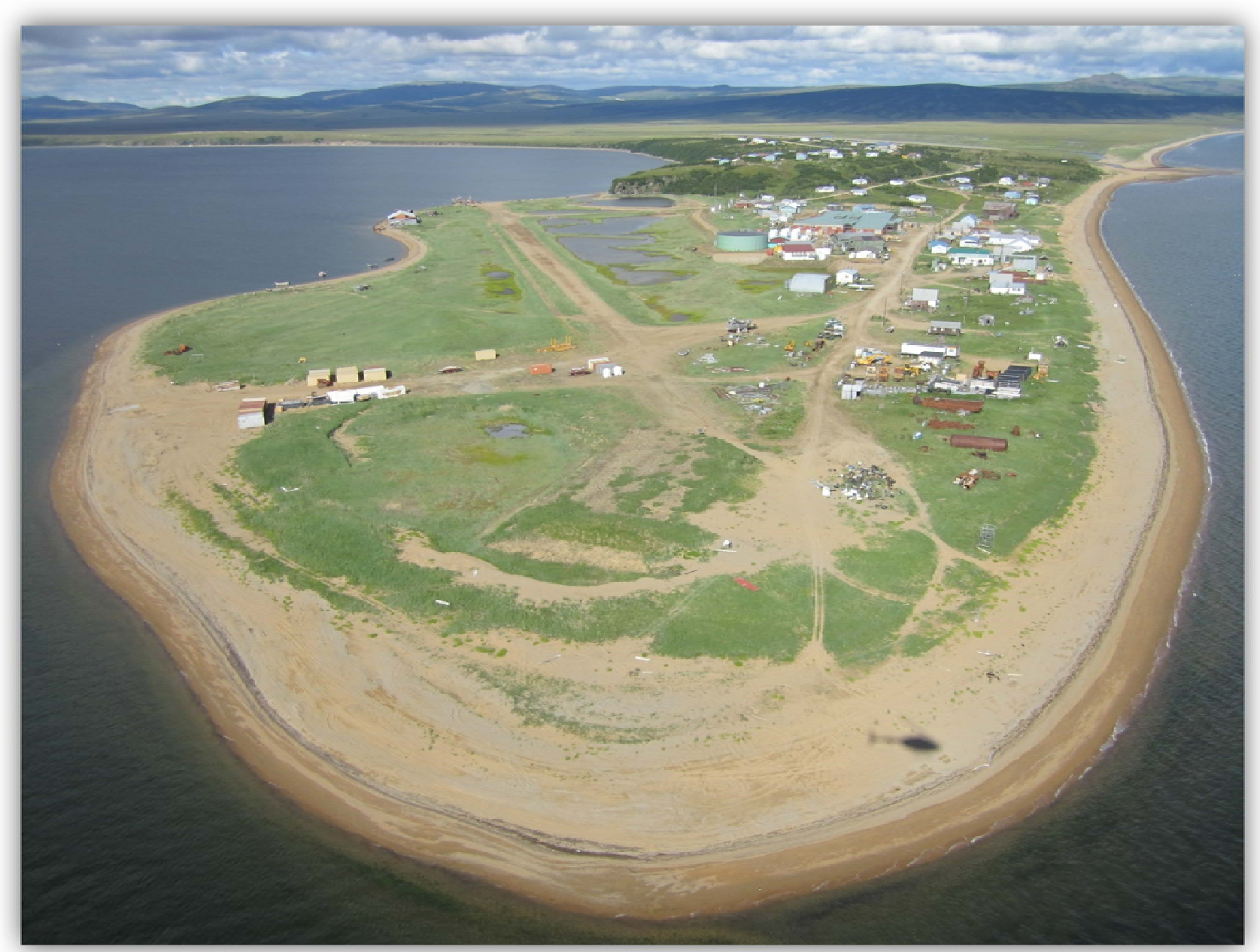

October 2012

Released by

STATE OF ALASKA

DEPARTMENT OF NATURAL RESOURCES

Division of Geological \& Geophysical Surveys

3354 College Rd.

Fairbanks, Alaska 99709-3707
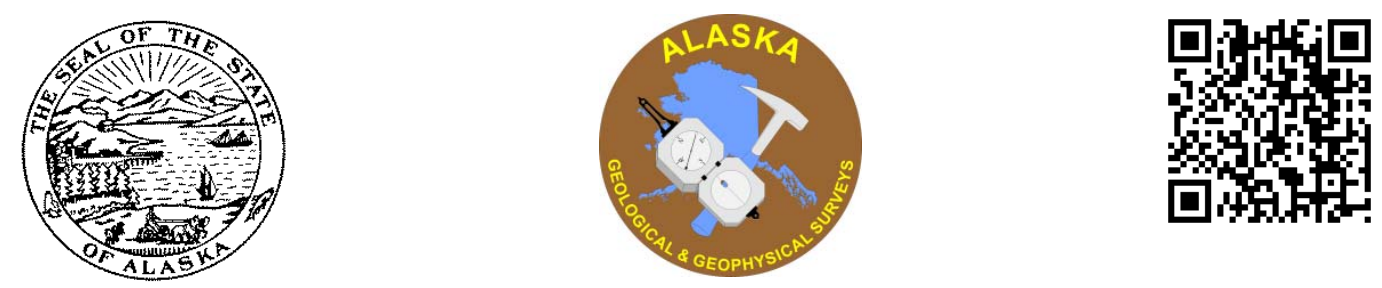



\title{
SPATIALLY REFERENCED OBLIQUE AERIAL IMAGERY OF THE GOLOVIN SHORELINE, JULY 2012 \\ by \\ Meagan R. DeRaps ${ }^{1}$ and Nicole E.M. Kinsman ${ }^{2}$
}

\begin{abstract}
This publication is funded with qualified outer continental shelf oil and gas revenues by the Coastal Impact Assistance Program, U.S. Fish \& Wildlife Service, U.S. Department of the Interior. The views and conclusions contained in this document are those of the authors and should not be interpreted as representing the opinions or policies of the U.S. Government. Mention of trade names or commercial products does not constitute their endorsement by the U.S. Government.
\end{abstract}

\begin{abstract}
In July 2012, a helicopter-based crew photographed approximately 22 miles (35 km) of shoreline near Golovin, Alaska, from the Yuonglik River delta southeast to Portage Creek. During this flight 572 oblique aerial photographs were collected and spatially referenced using a Garmin Dakota 20 handheld GPS. For a complete description of the image collection and file organization process please see the detailed metadata associated with this Raw Data File.
\end{abstract}

\section{DESCRIPTION OF OVERVIEW FIGURE}

For ease of use, the oblique aerial photographs are grouped into six separate .zip file downloads. The image group divisions are each composed of approximately 100 photographs, grouped by position along the shoreline. Specific image file names and image file groups are listed in the provided point shapefile. Photography of the shoreline in the vicinity of the town of Golovin can be found in the image group golovin-shoreline-obliques-4, and the community fish camp, including extensive ice-deposited sediments from the November 2011 storm, can be found in golovin-shoreline-obliques-2.

For quick reference, or for users without access to GIS software, figure 1 on the following page illustrates the geospatial location of the photographs in each .zip file bundle.

\footnotetext{
${ }^{1}$ Alaska Division of Geological \& Geophysical Surveys, 3354 College Rd., Fairbanks, Alaska 99709-3707; meagan.deraps@alaska.gov

${ }^{2}$ Alaska Division of Geological \& Geophysical Surveys, 3354 College Rd., Fairbanks, Alaska 99709-3707; nicole.kinsman@alaska.gov
} 


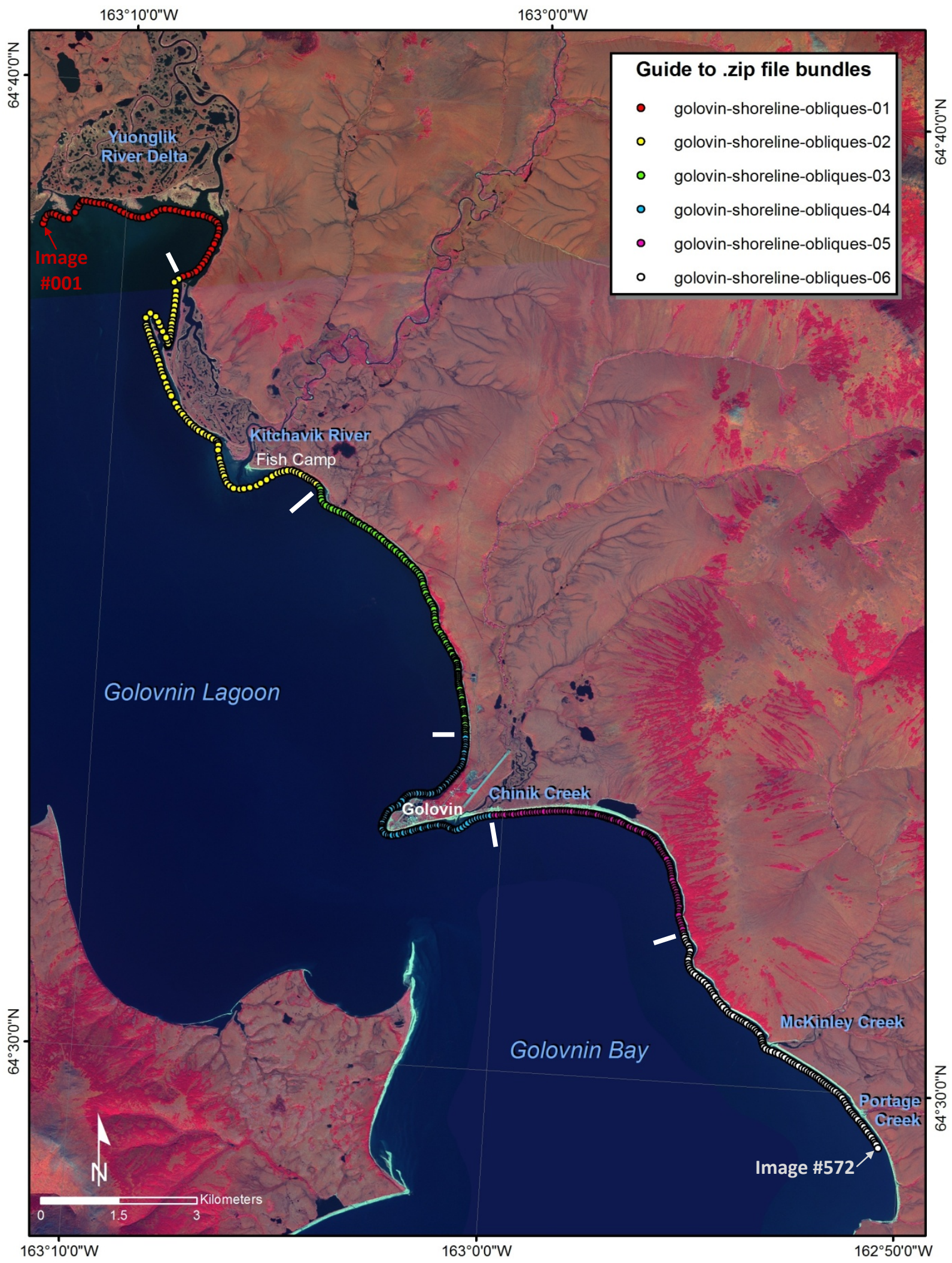

Figure 1. Locations of the 572 photographs included in this report. Thick white tick-marks along the color-coded flight path demarcate boundaries between .zip file bundles. Image numbers increase along the track from the northwest to the southeast. The base layer is a mosaic of 2009 SPOT5 infrared satellite images (vegetation appears red). 